\title{
Activation of Phasic Pontine-Wave Generator Prevents Rapid Eye Movement Sleep Deprivation-Induced Learning Impairment in the Rat: A Mechanism for Sleep-Dependent Plasticity
}

\author{
Subimal Datta, Vijayakumar Mavanji, Jagadish Ulloor, and Elissa H. Patterson \\ Sleep Research Laboratory, Department of Psychiatry and Program in Behavioral Neuroscience, Boston University School of Medicine, Boston, \\ Massachusetts 02118
}

\begin{abstract}
Animal and human studies of sleep and learning have demonstrated that training on various tasks increases subsequent rapid eye movement (REM) sleep and phasic pontine-wave (P-wave) activity, followed by improvement in performance on the learned task. It is well documented that REM sleep deprivation after learning trials blocks the expected improvement in performance on subsequent retesting. Our aim was to test whether experimentally induced P-wave generator activation could eliminate the learning impairment produced by post-training REM sleep deprivation. Rats were trained on a two-way active avoidance-learning task. Immediately thereafter, two groups of those rats received a control vehicle ( $100 \mathrm{nl}$ saline) microinjection and one group received a carbachol ( $50 \mathrm{ng}$ in 100 $\mathrm{nl}$ saline) microinjection into the P-wave generator. The carbachol-injected group and one of the two control saline microinjected groups were selectively deprived of REM sleep during a $6 \mathrm{hr}$ polygraphic recording session. All rats were then tested on the avoidance-learning task. The rats that received both the control saline injection and REM sleep deprivation showed learning deficits compared with the control saline-injected rats that were allowed to sleep normally. In contrast, the rats that received the carbachol microinjection and REM sleep deprivation demonstrated normal learning. These results demonstrate, for the first time, that carbachol-induced activation of the P-wave generator prevents the memory-impairing effects of post-training REM sleep deprivation. This evidence supports our hypothesis that the activation of the P-wave generator during REM sleep deprivation enhances a physiological process of memory, which occurs naturally during post-training REM sleep.
\end{abstract}

Key words: pontine wave; learning and memory; REM sleep; plasticity; carbachol; brainstem; locus subcoeruleus; rat; two-way active avoidance; consolidation

\section{Introduction}

Behavioral studies of learning and memory in both humans and animals provide considerable evidence to support the hypothesis that post-training rapid eye movement (REM) sleep is critical for and is the most favorable behavioral state for memory processing and improvement of learning (for review, see Fishbein and Gutwien, 1977; McGrath and Cohen, 1978; Pearlman, 1979; Smith, 1985, 1995; Dujardin et al., 1990; Karni et al., 1994; Stickgold, 1998; Datta, 2000; Maquet et al., 2003). Other studies have demonstrated that REM sleep is critical for neuronal plasticity, which is a critical mechanism for memory processing (Bramham and Srebro, 1989; Frank et al., 2001; Campbell et al., 2002; Guzman-Marin et al., 2003).

Different classes of memory formation appear to be processed

Received June 18, 2003; revised Dec. 18, 2003; accepted Dec. 19, 2003.

This work was supported by National Institutes of Health Grants NS34004 and MH59839. We thank Soma M. Datta for statistical analysis and for writing system software.

Correspondence should be addressed to Subimal Datta, Sleep Research Laboratory, Department of Psychiatry, Boston University School of Medicine, M-913, 715 Albany Street, Boston, MA 02118. E-mail: subimal@bu.edu.

DOI: 10.1523/JNEUROSCI.4111-03.2004

Copyright $\odot 2004$ Society for Neuroscience $\quad$ 0270-6474/04/241416-12\$15.00/0 by distinct memory systems in the brain (Cohen and Squire, 1980; Gabrieli, 1998; Kesner, 1998; Kim and Baxter, 2001; White and McDonald, 2002). Many recent studies have shown that the amygdala and hippocampus may be platforms for sleepdependent memory processing (Pavlides and Winson, 1989; Abel et al., 1997; Ribeiro et al., 1999, 2002; Poe et al., 2000; Abel and Lattal, 2001; Graves et al., 2001; Louie and Wilson, 2001). Although the amygdala, hippocampus, and possibly some other parts of the cerebral cortex process acquired information, it is not clear how REM sleep-regulating structures influence the way the hippocampus and amygdala process that information.

During REM sleep and in part of slow-wave sleep (SWS), phasic field potentials called pontine waves (P-waves) are generated in the pons (Brooks and Bizzi, 1963; Laurent and Ayalaguerrero, 1975; Sakai et al., 1976; Datta and Hobson, 1995). These field potentials are a reflection of phasic activation of a specific group of cells in the pons (Sakai and Jouvet, 1980; Datta et al., 1992, 1998; Datta and Hobson, 1994). It has been demonstrated that the functionally identified $\mathrm{P}$-wave generator cells project to the hippocampus and amygdala (Datta et al., 1998). Behavioral studies have shown that sleep-dependent improvement in learn- 
ing is positively correlated with $\mathrm{P}$-wave activity during REM sleep (Datta, 2000; Mavanji and Datta, 2003). Together, these anatomical and behavioral studies indicate that activation of the $\mathrm{P}$-wave generator might be involved in REM sleep-dependent memory processing in the rat.

To understand the role of P-wave generator activity in REM sleep-dependent learning and memory processing, the first task of the present study was to develop a method to selectively deprive REM sleep without disrupting SWS. Using this successful new method, we examined the effects of selective REM sleep deprivation on learning performance. We evaluated rat performance deficits immediately after training trials and REM sleep deprivation in relation to rats that received training followed by experimentally induced $\mathrm{P}$-wave generator activation and REM sleep deprivation.

\section{Materials and Methods}

Subjects. Experiments were performed on 30 male Sprague Dawley rats (Charles River, Wilmington, MA) weighing between 200 and $300 \mathrm{gm}$. Rats were housed individually at $24^{\circ} \mathrm{C}$ with ad libitum access to food and water. Lights were on from 7 A.M. to 7 P.M. (light cycle) and off from 7 P.M. to 7 A.M. (dark cycle). Principles for the care and use of laboratory animals in research, as outlined by the National Institutes of Health (1985), were strictly followed.

Surgical procedures for guide tube and electrode implantation. All surgical procedures were performed stereotaxically under aseptic conditions and were in accordance with the guidelines approved by the institutional animal care and use committee (Protocol 00-006). Animals were anesthetized by intramuscular injection of a mixture of ketamine $(80 \mathrm{mg} / \mathrm{ml})$ and xylazine $(10 \mathrm{mg} / \mathrm{ml})$ at a volume of $1 \mathrm{ml} / \mathrm{kg}$ body weight. Anesthetized rats were placed in a stereotaxic apparatus and secured using blunt rodent ear bars as described previously (Paxinos and Watson, 1997). A surgical plane of anesthesia was maintained with supplemental injections of the ketamine and xylazine mixture $(0.25 \mathrm{ml} / \mathrm{kg}$, i.m. $)$ every $1-2 \mathrm{hr}$, as necessary. The appropriate depth of anesthesia was judged by the absence of palpebral reflexes and absence of response to a tail pinch. Core body temperature was maintained at $37^{\circ} \pm 1^{\circ} \mathrm{C}$ with a thermostatic heating pad and a rectal feedback thermister probe. The scalp was cleaned and painted with providone iodine. A scalp incision was made, and the skin was retracted. The skull surface was cleaned in preparation for guide tube and electrode implantation. After completion of the surgical procedure, animals were administered saline ( $5 \mathrm{cc}$, s.c.) to prevent dehydration and the antibiotic gentamicin $(0.1 \mathrm{cc}$, i.m. $)$ to control any potential postsurgical infection. Potential postoperative pain was controlled with buprenorphine $(0.05 \mathrm{cc}$, s.c.).

To record the behavioral states of vigilance, cortical electroencephalogram (EEG), dorsal neck muscle electromyogram (EMG), electrooculogram (EOG), hippocampal EEG (to record theta wave), and pontine EEG (to record P-wave) recording electrodes were chronically implanted, as described previously (Datta, 2000, 2002; Datta et al., 2001). In addition, a stainless steel guide tube (26 gauge) with an equal length stylet inside was stereotaxically implanted $2 \mathrm{~mm}$ above the P-wave recording electrodes for the microinjection of control saline or carbachol solution into the P-wave generator (in relation to stereotaxic "0": posterior, 0.80 ; lateral, 1.3; horizontal, 2.0) of freely moving rats as described previously (Mavanji and Datta, 2003). The bipolar P-wave recording electrode and guide tube were placed so that the tip of the injector terminated close to the P-wave recording electrode (Mavanji and Datta, 2003). All electrodes and guide tubes were secured to the skull with dental acrylic. Electrodes were crimped to mini-connector pins and brought together in a plastic connector. Immediately after surgery, animals were placed in recovery cages and monitored for successful recovery from anesthesia and surgery. Successful recovery was gauged by the return of normal postures, voluntary movement, and grooming. At this point animals were transferred to their normal housing. After a postsurgical recovery period of 3-7 d, rats were habituated to the sound-attenuated recording cage (electrically shielded: $2.5 \times 1.5 \times 1.5$ feet), shuttle box, and free-moving recording conditions for $7 \mathrm{~d}$.

Avoidance learning. The apparatus that was used is an automated twoway shuttle scan shock-avoidance box $(45.7 \times 20.3 \times 30.5 \mathrm{~cm})$ with sides made of high-grade acrylic. This apparatus has been described in detail previously (Datta, 2000; Mavanji and Datta, 2003). After 15 min of acclimatization, learning trials began. During acclimatization and the learning trials, the rats could move freely from one compartment to the other within the shuttle box. Rats were trained on a massed 30-trial shuttle box two-way active avoidance (TWAA) task. The procedures for the conditioned stimulus (CS) and unconditioned stimulus (UCS) have been detailed previously (Datta, 2000; Mavanji and Datta, 2003). In brief, a tone $(3600 \mathrm{~Hz}, 65 \mathrm{db})$ and a pulsatile light $(2.5 \mathrm{~Hz})$ were presented as a CS in the compartment with the animal and paired $5 \mathrm{sec}$ later with $0.3 \mathrm{~mA}$ scrambled foot shock (UCS) delivered through the floor grid. To avoid receiving a foot shock, the rat had $5 \mathrm{sec}$ to move to the opposite compartment. If the animal did not move to the other compartment, UCS was delivered for a maximum of $5 \mathrm{sec}$ and CS ended with UCS. While receiving UCS, if the animal moved to the other compartment, both CS and UCS ended immediately. The intertrial interval was variable with a mean of $60 \mathrm{sec}$.

Since the discovery of REM sleep, animal studies of sleep and learning have used various hippocampally and non-hippocampally mediated learning paradigms (for review, see Smith, 1985; Stickgold, 1998). In this study, we have used a two-way active avoidance-learning task that involves both hippocampal and non-hippocampal structures for learning and memory processing (Smith and Young 1980; Ambrosini et al., 1988; Ramirez and Carrer, 1989; Bramham et al., 1994). The involvement of the hippocampus and some non-hippocampal structures in learning and memory processing is supported by many other studies (Squire et al., 1990; LeDoux, 1992; Silva et al., 1992; Izquierdo et al., 1995; Hatfield et al., 1996; Rempel-Clower et al., 1996; Poremba and Gabriel, 1997; Young et al., 1997; Gallagher et al., 1999; Vazdarjanova and McGaugh, 1999). One recent anatomical study provided evidence that P-wave-generating cells project monosynaptically to both the hippocampus and nonhippocampal structures involved in the learning process (Datta et al., 1998). Because P-wave-generating cells project to both hippocampal and non-hippocampal structures, the activation of $\mathrm{P}$-wave-generating cells may modulate both hippocampally and non-hippocampally mediated learning processes. Therefore, the selection of a two-way active avoidance-learning task, which involves both hippocampal and nonhippocampal structures, was appropriate to study the relationship between P-waves, REM sleep, and learning.

Intracerebral microinjection system. The microinjection system consisted of a 32 gauge stainless steel injector cannula with a 26 gauge collar that extended $2.0 \mathrm{~mm}$ beyond the implanted guide tube. The collar was connected to a $1.0 \mu \mathrm{l}$ motor-driven microsyringe with polyethylene (PE) 20 tubing. After the injection system was filled with control vehicle or carbachol, a small air bubble was introduced into the PE tubing to monitor the fluid movement during the injection. While the animal was connected to the recording system, the stylet was removed and a control vehicle-filled ( $100 \mathrm{nl}$ volume of $0.9 \%$ saline) or carbachol-filled (50 ng in $100 \mathrm{nl}$ of saline) injector was introduced through the guide tube. One minute after the insertion of the injector cannula, $100 \mathrm{nl}$ of control saline or carbachol was microinjected over a $60 \mathrm{sec}$ period. The cannula was gently withdrawn $2 \mathrm{~min}$ after the injection, and the stylet was reintroduced inside the guide tube. All of these injections were unilateral. During the microinjections, animals were free to move around the cage with the cannula in place. The extended tubing makes it possible to inject while the animals are moving freely (Datta et al., 2002). Immediately after the microinjection procedure, polygraphic variables were recorded continuously for 6 hrs (between 10 A.M. and 4 P.M.) when rats would normally be sleeping (Datta, 2000). The optimum dose of carbachol (50 ng) was predetermined from our earlier P-wave generator mapping studies (Datta et al., 1998, 1999; Mavanji and Datta, 2003).

Adaptation recording session. After the postsurgical recovery period of 3-7 d, rats were habituated to the experimenter, the sound-attenuated recording cage, the shuttle box, and the free-moving recording conditions for $7 \mathrm{~d}$. During recovery, habituation, and free-moving recording 
conditions (adaptation recording sessions), all rats were housed under the same $12 \mathrm{hr}$ light/dark cycle with ad libitum access to food and water.

Polygraphic recordings and REM sleep deprivation setup. To record cortical EEG, EMG, EOG, hippocampal EEG, and pontine EEG in a freely moving condition, each rat's head plug was mated to a 24-pin male connector that in turn was connected to a 24-pin commutator. Signals from this commutator were sent to a polygraph (located in the next room; Grass Model 79; Grass Instrument Co., Quincy, MA) via its electrode board (located inside the recording chamber). To allow rats to move freely inside the recording cage while maintaining the head plug connection, a counterbalanced connecting cable and a mechanical pulley system (attached to the roof of the recording chamber) were used. In a separate room, polygraphic signs and the activities of the rat were continuously observed on a computer and a video monitor, respectively, to identify ongoing behavioral stages.

For the purpose of REM sleep deprivation, the beginning of each REM sleep episode was identified by observation of ongoing polygraphic records. From the room adjacent to the rat, the experimenter pressed a mechanical lever within 2-3 sec of REM sleep onset, the animal's head was gently lifted, and the animal was awakened. Because this is the first study to use this technique for the selective deprivation of physiologically identified REM sleep in the rat, following is the technical description of this method. This "head-lifting method" for REM sleep deprivation requires a small, spring-action mechanical lever, three pulleys with equal wheel diameter, and a flexible, lightweight wire. The first pulley is positioned on the ceiling at a $90^{\circ}$ angle, 3 feet above the commutator. The second pulley is located in the next room, positioned at the same height as the first pulley. The second pulley hangs from the ceiling above the computer monitor used for observing polygraphic signs. The third pulley is on the table with the computer monitor. The mechanical lever is fixed to the table $\sim 6$ inches in front of the monitor. One end of the wire is tied to the commutator, and the other end goes up, passes through the first, second, and third pulleys, and then is tied to the mechanical lever. A relaxed spring keeps the mechanical lever in the up position. As needed, manually applied incremental downward pressure on the lever handle produces incremental lever action to raise the rat's head by up to 2 inches and terminate REM sleep. Using this method during the experimental recording session, in two groups of rats (groups 2 and 3) REM sleep episodes were terminated prematurely within $3-5 \mathrm{sec}$ of their appearance.

Typically, the following three methods are used to deprive REM sleep in the rat. (1) The flowerpot method, also known as water tank, platform, disc over water, or pedestal method (Bhanot et al., 1989; Rechtschaffen et al., 1989; Thakkar and Mallick, 1993; Hicks et al., 1997): The flowerpot method has been shown to induce high stress, and the resultant sleep deficits, including disruption of SWS, are considered to be caused by overwhelming nonspecific stress rather than selective REM sleep deprivation (Vogel, 1975; Rechtschaffen et al., 1999; Hamdi, 2000). (2) The moving disc or drum method (Stefurak et al., 1977; Rechtschaffen and Bergmann, 1995; Feng et al., 2000; Campbell et al., 2002): Although less stressful than the flowerpot method, this procedure significantly reduces the amount of SWS and introduces an unrelated variable physical activity. (3) Gentle handling (Vogel, 1975; Ocampo-Garces et al., 2000; Sei et al., 2000; Vyazovskiy et al., 2002): This method disrupts SWS in addition to REM sleep. To reduce some of the disadvantages encountered with the existing methods of REM sleep deprivation, we designed a new method that should minimize extraneous stress and physical activity and eliminate the need for the experimenter's physical proximity to the rat. The head-lifting method successfully eliminated $90-95 \%$ of total REM sleep for the $6 \mathrm{hr}$ recording sessions without significantly reducing SWS. These results indicate that this technique is a significant improvement over existing methods of selective REM sleep deprivation. It is also important to note that this improved technique further substantiates the results of earlier seminal studies that used other REM sleep deprivation methods to show that post-training REM sleep deprivation can partially or even totally block improved task performance on subsequent retesting (Smith, 1995).

Determination of behavioral states. For the purpose of determining possible effects on sleep and wakefulness, polygraphic data were captured on-line in a computer using "Gamma" software (Grass product group, Astro-Med, West Warwick, RI). From this captured data, four behavioral states were distinguished and scored visually using "Rodent Sleep Stager" software (Grass product group, Astro-Med). These four states were as follows: (1) wakefulness (W): low voltage $(50-80 \mu \mathrm{V})$ and fast $(30-50$ $\mathrm{Hz}$ ) cortical EEG, high-amplitude tonic and phasic EMG bursts, presence of eye movements in the EOG, gross bodily movements, and an absence of P-waves; (2) SWS: spindling and high-voltage $(200-400 \mu \mathrm{V})$ slow waves $(0.3-15 \mathrm{~Hz})$ in the cortical EEG, EMG tonus lower than during W, absence of eye movements, and absence of P-waves; (3) transition state between SWS and REM sleep (tS-R): during this stage, cortical EEG is a mixture of partly low-amplitude $(50-80 \mu \mathrm{V})$, high-frequency $(15-25 \mathrm{~Hz})$ and high-amplitude $(200-300 \mu \mathrm{V})$, low-frequency $(5-10 \mathrm{~Hz})$ waves. The EMG tone is absent or progressively diminished. Eye movements are absent in the EOG record. Theta frequency waves start to appear in the hippocampal EEG. Spiky P-waves (10-20 per minute) start to appear in the pontine EEG. These P-waves are mostly the single-spike type. (4) REM sleep: low voltage $(50-100 \mu \mathrm{V})$ and fast $(20-40 \mathrm{~Hz})$ cortical EEG, presence of muscle atonia, rapid eye movements, and theta waves $(4-7 \mathrm{~Hz})$ only in the hippocampal EEG, and increased occurrence of P-waves, most of them occurring in clusters of two to three. The behavioral states of W, SWS, tS-R, and REM sleep were scored in successive 5 sec epochs. This epoch length allowed us to quantify the short periods of REM sleep $(3-5 \mathrm{sec})$ in groups 2 and 3 . These nascent $3-5 \mathrm{sec}$ periods of REM sleep were necessary to identify the ongoing REM sleep episode so that it could be terminated. We calculated the total amount of time spent in motor activities (exploratory and grooming behavior) after carbachol and control saline microinjections into the P-wave generator, as observed in the video monitor. Mean EMG amplitude was calculated from the polygraphic records.

Experimental design. After the adaptation recording sessions, all rats underwent two sessions of baseline recording for electrode testing and additional habituation with the recording setup. During these baseline recording sessions, pontine EEG was studied carefully to identify rats with good P-wave activity during REM sleep. Of the original 38 rats, 30 exhibited good quality P-wave activity during REM sleep and thus underwent a third, and final, baseline recording session. For baseline recordings, rats were placed in the shuttle box for $45 \mathrm{~min}$ (9:00-9:45 A.M.) and transferred to a recording cage for $6 \mathrm{hr}$ of polygraphic recordings (between 10 A.M. and 4 P.M.) on 3 consecutive days. On the final baseline recording day, animals received a single microinjection (between 9:58 A.M. and 10:00 A.M.) of control saline in the P-wave generator $(n=$ 30 rats). On the day after the final baseline recording session, rats were placed in the shuttle box at 9 A.M., and after 15 min of acclimatization, the active avoidance-learning paradigm or "training trial session" with CS began. After 30 trials (as described above), rats were transferred to the polygraphic recording cage. At this point, the 30 rats were randomly divided into three treatment groups. (1) Group 1 ( $n=10$ rats): While the animals were connected to the polygraphic recording system, rats were microinjected with control saline (100 nl). They were then recorded for 6 hr (between 10 A.M. and 4 P.M.) of undisturbed sleep-wakefulness [hereafter group 1 is labeled as "normal sleep control" (NSC)]. At the end of the $6 \mathrm{hr}$ recording session, the "test trial session" began; that is, animals were again tested on the CS-UCS task for 30 trials (between 4:05 and 4:50 P.M.). (2) Group 2 ( $n=10$ rats): The experimental protocol for these animals was almost identical to the protocol described above for NSC group, except that for group 2 animals, REM sleep episodes were terminated at the beginning (within 3-5 sec) of each episode while the animals were connected to the polygraphic recording system [hereafter group 2 is labeled as "REM sleep deprived" (RSD)]. (3) Group 3 ( $n=10$ rats): The experimental protocol for these animals was almost identical to the protocol described above for the RSD group, except that this group received a microinjection of carbachol (50 $\mathrm{ng}$ in $100 \mathrm{nl}$ ) in the P-wave generator instead of control saline [hereafter group 3 is labeled as "REM sleep deprived and P-wave generator activated" (RSD-PA)].

At the end of all recording sessions and before perfusion, with the use of the same injector used for control and carbachol microinjections, 100 $\mathrm{nl}$ of black ink was microinjected at each injection site. Rats were then deeply anesthetized with pentobarbital $(60 \mathrm{mg} / \mathrm{kg}$, i.p.) and perfused transcardially with heparinized cold phosphate buffer (0.1 M, pH 7.4) 
followed by $4 \%$ paraformaldehyde in $0.1 \mathrm{~m}$ phosphate buffer. The brains were then removed and processed for staining and histological localization of injection sites as described previously (Datta et al., 2001; Mavanji and Datta, 2003).

Data analysis. The polygraphic measures provided the following dependent variables that are quantified for each trial: (1) percentage of recording time spent in W, SWS, tS-R, and REM sleep, (2) latency to onset of the first episode of REM sleep after the onset of recordings, (3) total number of REM sleep episodes, (4) mean duration of REM sleep episodes, and (5) P-wave density (waves per minute) in REM sleep. The number of REM sleep episodes in group NSC was counted by how many times the animal entered into REM sleep that lasted at least $3 \mathrm{sec}$. In groups RSD and RSD-PA (REM sleep-deprived animals), the number of REM sleep episodes was the number of times REM was terminated using the head-lifting method. For latency analysis, the data collection began immediately after the microinjection. All of these variables from the final baseline recording day (before shuttle box trials) were analyzed using one-factor ANOVA (between groups NSC, RSD, and RSD-PA), using StatView statistical software (Abacus Concepts, Berkeley, CA). These analyses were performed to confirm that the three distinct treatment groups were not statistically distinguishable before the shuttle box trials. Baseline recording variables of the three treatment groups were then combined and labeled as baseline treatment group for the next steps of statistical analysis. After shuttle box training trials, all of the above mentioned sleep-wake variables in groups NSC, RSD, and RSD-PA rats were analyzed using one-factor ANOVAs to determine the sleep-wake effect of avoidance learning and carbachol microinjection into the P-wave generator. After ANOVA, post hoc Scheffé $F$ tests were performed to determine the individual levels of significant difference between group NSC and group RSD, group NSC and group RSD-PA, and group RSD and group RSD-PA treatment protocols.

For the analysis of performance on the TWAA-learning task, the 30 learning trials of each session were divided into six blocks of five trials, and the percentage of successful avoidances was calculated for each block (Datta, 2000; Mavanji and Datta, 2003). The percentages of avoidance data during training trials were subjected to two-way ANOVA (group $\times$ blocks) to ensure that the learning curves of the three treatment groups were not different during the training trials. For the next steps of statistical analysis, training trial data of the three groups was combined into one group. Next, the percentages of avoidance data during training trials (combined group) and test trials of the three different treatment groups were analyzed using two-way ANOVA (trial $\times$ block) with block as a repeated measure, followed by a post hoc Scheffé $F$ test. These analyses were performed to determine the differences in learning curves between the first session of combined group (training trials session, before $6 \mathrm{hr}$ undisturbed polygraphic recordings) and the second sessions (test trials sessions, after $6 \mathrm{hr}$ polygraphic recordings) of NSC, RSD, and RSD-PA treatment groups. This difference represents a quantitative measure of the amount of information retained from the first training session. Similarly, the comparison between NSC, RSD, and RSD-PA treatment groups test trials was done to determine whether there was any effect on the learning curve after REM sleep deprivation with or without microinjection of carbachol into the P-wave generator. The improvement of performance between training trials and test trials was calculated by subtracting the percentage of avoidance in the first two blocks of training from the percentage of avoidance in the first two blocks of test as described previously (Datta, 2000; Mavanji and Datta, 2003).

\section{Results}

In the first two baseline polygraphic recording (electrode testing) sessions, 30 rats exhibited good quality $\mathrm{P}$-waves during $\mathrm{tS}-\mathrm{R}$ and REM sleep. On the basis of in vivo pharmacological responses to carbachol microinjection into the $\mathrm{P}$-wave generator and postmortem histological identification, recording and microinjection sites were identified as within the P-wave generator (Fig. 1). Histological examination revealed that our microinjection of a $100 \mathrm{nl}$ volume of dye diffused only $0.1-0.15 \mathrm{~mm}$ from the center of microinjection (Fig. 1), indicating that the microinjection of car- bachol did not diffuse outside of the P-wave generator. Before learning trials, in the final $6 \mathrm{hr}$ baseline recording session, total percentages of time spent in W, SWS, tS-R, and REM sleep and $\mathrm{P}$-wave density were not significantly different (one-factor ANOVA) between the three groups of animals. Thus, the groups were initially equal in terms of time spent in W, SWS, tS-R, and REM sleep and P-wave density for the final $6 \mathrm{hr}$ baseline recording session.

\section{Effects of REM sleep deprivation on wake-sleep states}

After a session of training trials, rats in groups NSC and RSD received control saline microinjections, and group RSD-PA received a carbachol microinjection into the $\mathrm{P}$-wave generator. All groups were then recorded in the polygraph for $6 \mathrm{hr}$. During this polygraphic recording session, rats in groups RSD and RSD-PA were subjected to the REM sleep deprivation protocol. The total percentages of REM sleep in groups RSD $(0.58 \pm 0.03 \%)$ and RSD-PA $(0.56 \pm 0.02 \%)$ were drastically reduced compared with the total percentage of REM sleep in group NSC (14.12 $\pm 2.59 \%)$ (Fig. 2). These results demonstrate that the deprivation method used for this study effectively reduced the total amount of REM sleep. Statistical comparisons (one-factor ANOVAs) between the three groups revealed significant differences in the time spent in $\mathrm{W}\left(F_{(2,27)}=14.945 ; p<0.0001\right), \mathrm{tS}-\mathrm{R}\left(F_{(2,27)}=15.728 ; p<\right.$ $0.0001)$, and REM sleep $\left(F_{(2,27)}=165.076 ; p<0.0001\right)$ but not in SWS $\left(F_{(2,27)}=1.956 ; p=0.1609\right)$. To determine the effects of REM sleep deprivation alone, sleep-wake data were compared between groups NSC and RSD. Post hoc Scheffé $F$ test showed that group RSD animals spent significantly more time in wakefulness than group NSC animals $(69.78 \%$ more; $F=12.0 ; p<0.001)$ (Fig. 2). Group RSD animals spent significantly less time than group NSC in tS-R (62.7\% less; $F=10.3 ; p<0.001)$ and REM sleep (95.9\% less; $F=123.63 ; p<0.001$ ) (Fig. 2 ). Although the percentage of REM sleep in the group RSD animals was significantly less than in the group NSC animals, the number of REM sleep episodes was significantly higher in the RSD group (Fig. 2). The latencies to REM sleep episode in the NSC and RSD groups of animals were comparable (Fig. 2). This increased number of REM sleep episodes in the RSD group of animals is likely caused by the increased REM sleep pressure caused by the REM sleep deprivation. The fact that the REM sleep-deprived rats had a tendency to enter REM sleep directly from SWS without entering into $\mathrm{tS}-\mathrm{R}$ suggests that increased REM sleep pressure in the REM sleep-deprived rats may also be responsible for the reduction in the total amount of time spent in $\mathrm{tS}-\mathrm{R}$.

\section{Sleep-wake state effects of carbachol microinjection into the $\mathrm{P}$-wave generator}

To determine the effects of carbachol microinjection into the $\mathrm{P}$-wave generator, sleep-wake data collected during the posttraining recording sessions were compared between groups RSD and RSD-PA. Post hoc Scheffé $F$ test and one-factor ANOVAs showed that the total percentages of W, SWS, tS-R, and REM sleep were not significantly different between groups RSD and RSD-PA (Fig. 2). The latencies to the first episode of REM sleep and total numbers of REM sleep episodes were not significantly different in the group NSC and group RSD animals (Fig. 2). These results demonstrate that the microinjection of carbachol into the P-wave generator did not significantly change the sleepwake parameters measured. Similarly, the total percentages of time spent in active motor behavior (saline vs carbachol: $9.8 \pm$ 3.8 vs $7.9 \pm 4.1 \%$ ) and mean EMG amplitudes during those active motor behaviors $(198 \pm 34$ vs $185 \pm 41 \mu \mathrm{V})$ were not 
significantly different between groups RSD and RSD-PA. These results indicate that the microinjection of carbachol into the P-wave generator did not significantly alter the total amount of time and intensity of motor activities.

\section{Effects of avoidance-learning training on P-wave activity}

The $\mathrm{P}$-wave is normally present during both $\mathrm{tS}-\mathrm{R}$ and REM sleep; however, to determine the effect of avoidance training trials on the $\mathrm{P}$-wave density change, we quantified P-waves only during REM sleep episodes. In the final baseline recording session, the REM sleep P-wave densities were comparable (one-factor ANOVA; $\left.F_{(2,27)}=1.062 ; p=0.187\right)$ in group NSC $(36.6 \pm 4.2)$, group RSD $(38.6 \pm 3.5)$, and group RSD-PA $(38.9 \pm 5.1)$ animals. In the polygraphic recording session after avoidance-learning training trials, however, the REM sleep P-wave density in group NSC animals (56.4 \pm 6.2$)$ was significantly higher $(54.1 \%$ higher; $F=42.32$, $p<0.001)$ than this group's baseline value $(36.6 \pm 4.2)$. These results demonstrate that avoidance-learning trials increased REM sleep P-wave density.

\section{Carbachol microinjection into the P-wave generator: effects on P-wave activity}

To determine what effect carbachol microinjection into the $\mathrm{P}$-wave generator had on $\mathrm{P}$-wave activity, the $\mathrm{P}$-wave density during post-training recording sessions was compared in group RSD and RSD-PA animals, because both groups were REM sleep deprived. To calculate $\mathrm{P}$-wave density, the total number of $\mathrm{P}$-waves during the entire $6 \mathrm{hr}$ recording session was counted and expressed as $\mathrm{P}$-wave density (waves per minute) for the entire recording session. In group $\mathrm{RSD}, \mathrm{P}$-waves were seen only during $\mathrm{tS}-\mathrm{R}$ and the short periods of REM sleep before it was terminated by the experimenter; however, in group RSD-PA animals, $\mathrm{P}$-waves were present not only during $\mathrm{tS}-\mathrm{R}$ and these short periods of REM sleep, but also during the SWS that lasted for $\sim 4 \mathrm{hr}$ (Fig. 3). These stateindependent $\mathrm{P}$-waves in group RSD-PA animals are attributable to the application of carbachol in the P-wave generator. The mean P-wave density of group RSD-PA animals (40.2 \pm 9.4) was significantly higher $(793 \%$ higher; $F=68.5 ; p<0.001)$ compared with group RSD animals ( $4.5 \pm$ 6.2). During the $6 \mathrm{hr}$ recording sessions after avoidance training and local microinjections into the $\mathrm{P}$-wave generator, the mean total $\mathrm{P}$-wave count of group

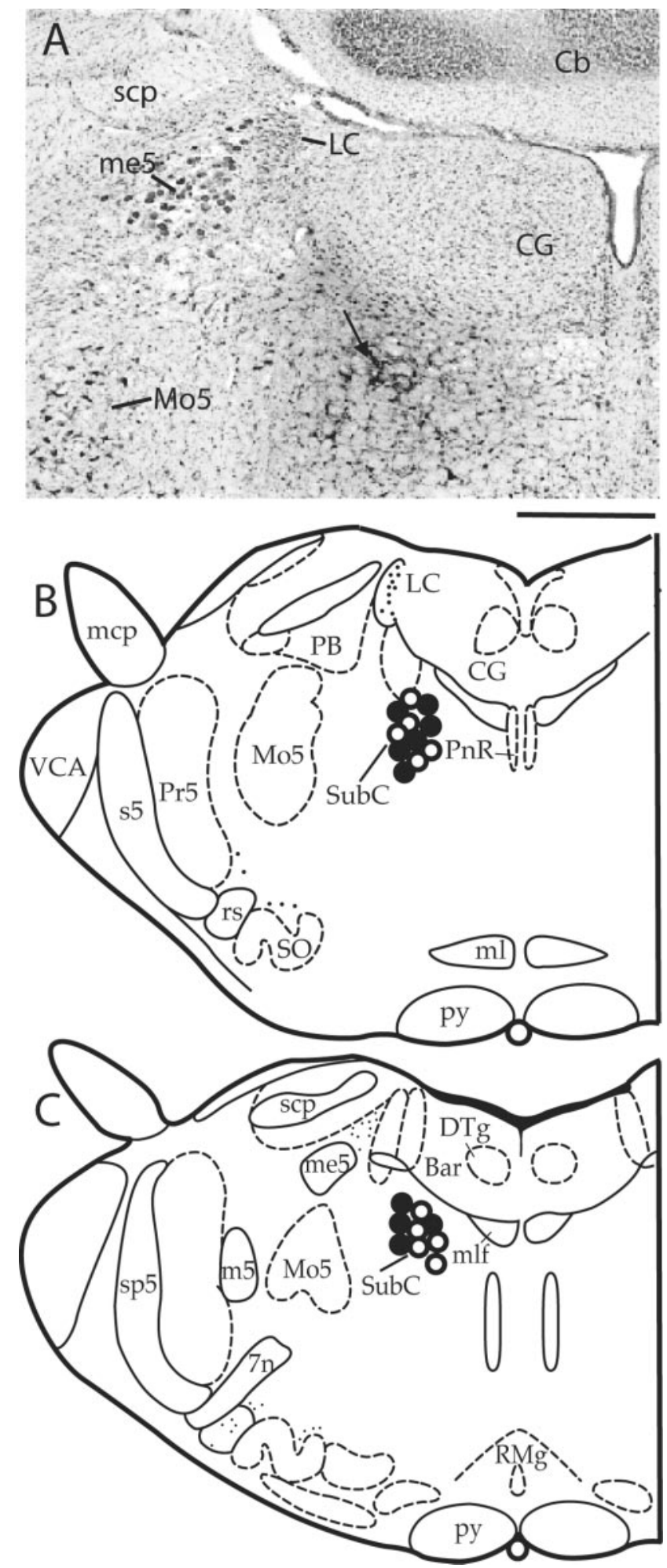

Figure 1. Histological localization of carbachol and control saline microinjection sites in the P-wave generator. $A$, Coronal section of rat brainstem showing an example of a carbachol microinjection site in the P-wave generator (arrow indicates dorsal part of the subcoeruleus nucleus). To mark the carbachol microinjection site, $100 \mathrm{nl}$ of black ink was microinjected using the same injector in the site (arrow points to the carbachol and ink injection site). B, C, Schematic coronal sections through the brainstem showing anatomical locations of control saline $(O ; n=10$; group 2 rats) and carbachol (O; $n=10$; group 3 rats) microinjection sites. 7n, Facial nerve or its root; Bar, Barrington's nucleus; Cb, cerebellum; CG, central gray; DTg, dorsal tegmental nucleus; LC, locus coeruleus; m5, motor root of trigeminal nucleus; mcp, mid cerebellar peduncle; me5, mesencephalic trigeminal tract; ml, medial lemniscus; mlf, medial longitudinal fasciculus; M05, motor trigeminal nucleus; PB, parabrachial nucleus; PnR, pontine raphe nucleus; $\mathrm{Pr} 5$, principal sensory trigeminal nucleus; py, pyramidal tract; RMg, raphe magnus nucleus; rs, rubrospinal tract; $s 5$, sensory root trigeminal nucleus; scp, superior cerebellar peduncle; SO, superior olive nucleus; sp5, spinal trigeminal tract; SubC, subcoeruleus nucleus; VCA, ventral cochlear nucleus. Scale bar: $A, 400 \mu \mathrm{m} ; B, C, 1.2 \mathrm{~mm}$. 

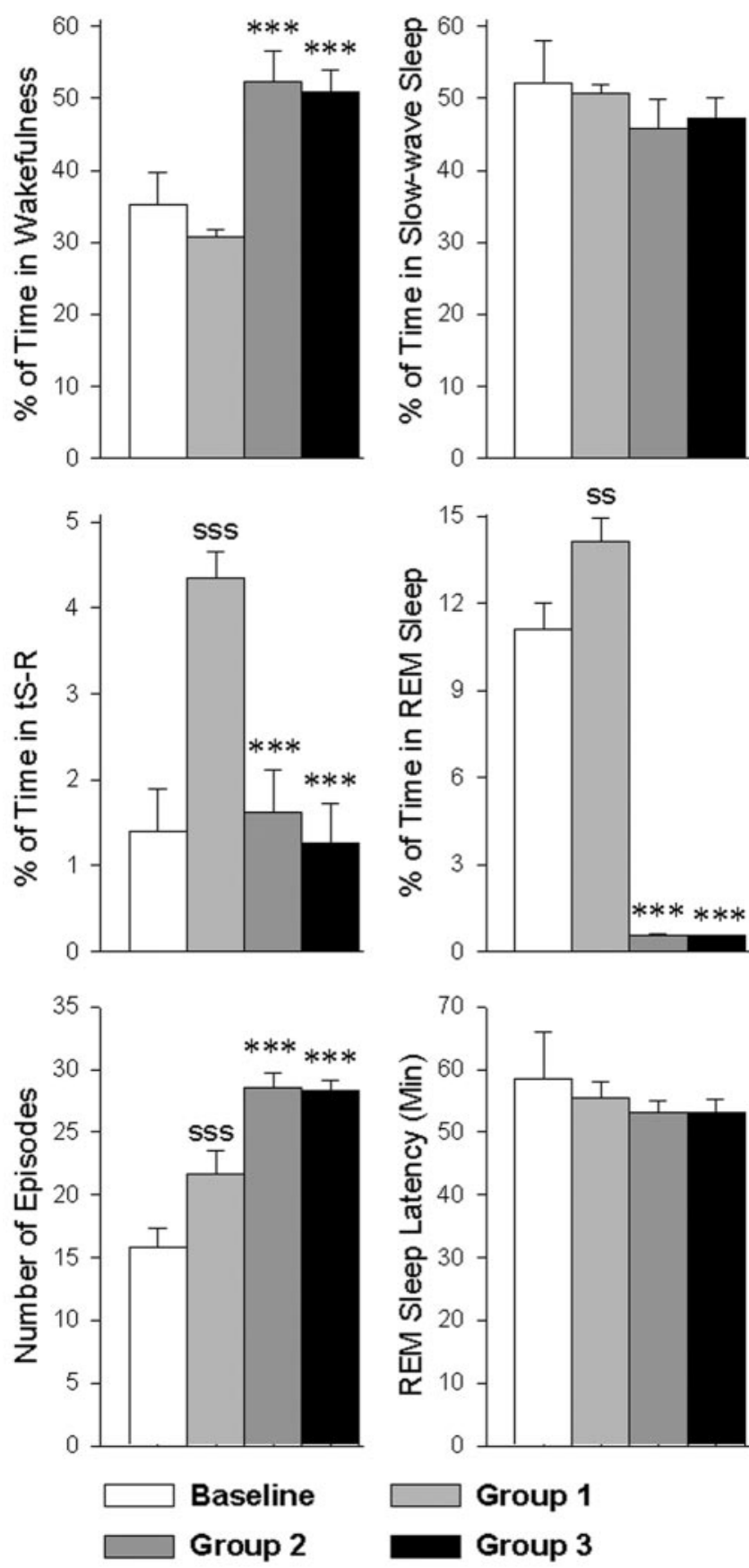

Figure 2. The effects of two-way active avoidance-learning trials and selective REM sleep deprivation on wakefulness, slow-wave sleep, $t S-R$, and REM sleep over a $6 \mathrm{hr}$ period. Baseline $(n=30$; mean $\pm \mathrm{SE}): 6 \mathrm{hr}$ of undisturbed sleep-wake recordings after a microinjection of control saline (100 $\mathrm{nl})$ in the P-wave generator; group $1(n=10$; mean $\pm \mathrm{SE})$ : training trials followed by microinjection of control saline $(100 \mathrm{nl})$ into the $P$-wave generator and then $6 \mathrm{hr}$ of undisturbed sleep-wake recordings; group $2(n=10$; mean \pm SE): training trials followed by microinjection of control saline ( $100 \mathrm{nl})$ into the P-wave generator and then $6 \mathrm{hr}$ of sleep-wake recordings while animals were selectively deprived of REM sleep; group $3(n=10$; mean $\pm \mathrm{SE})$ : training trials followed by microinjection of carbachol ( $50 \mathrm{ng}$ in $100 \mathrm{nl}$ ) into the P-wave generator and then $6 \mathrm{hr}$ of sleep-wake recordings while animals were selectively deprived of REM sleep. Post hoc Scheffé $F$ test: " $S$ " represents the comparison between baseline and group 1 to evaluate the effects of learning trials, and asterisk represents the comparison with group 1 (control group) to evaluate the effects of REM sleep deprivation in group 2, and the combination of REM sleep deprivation and carbachol microinjection into the P-wave generator in group 3. SS: $p<0.01 ;$ SSS or ${ }^{* * *} p<0.001$.
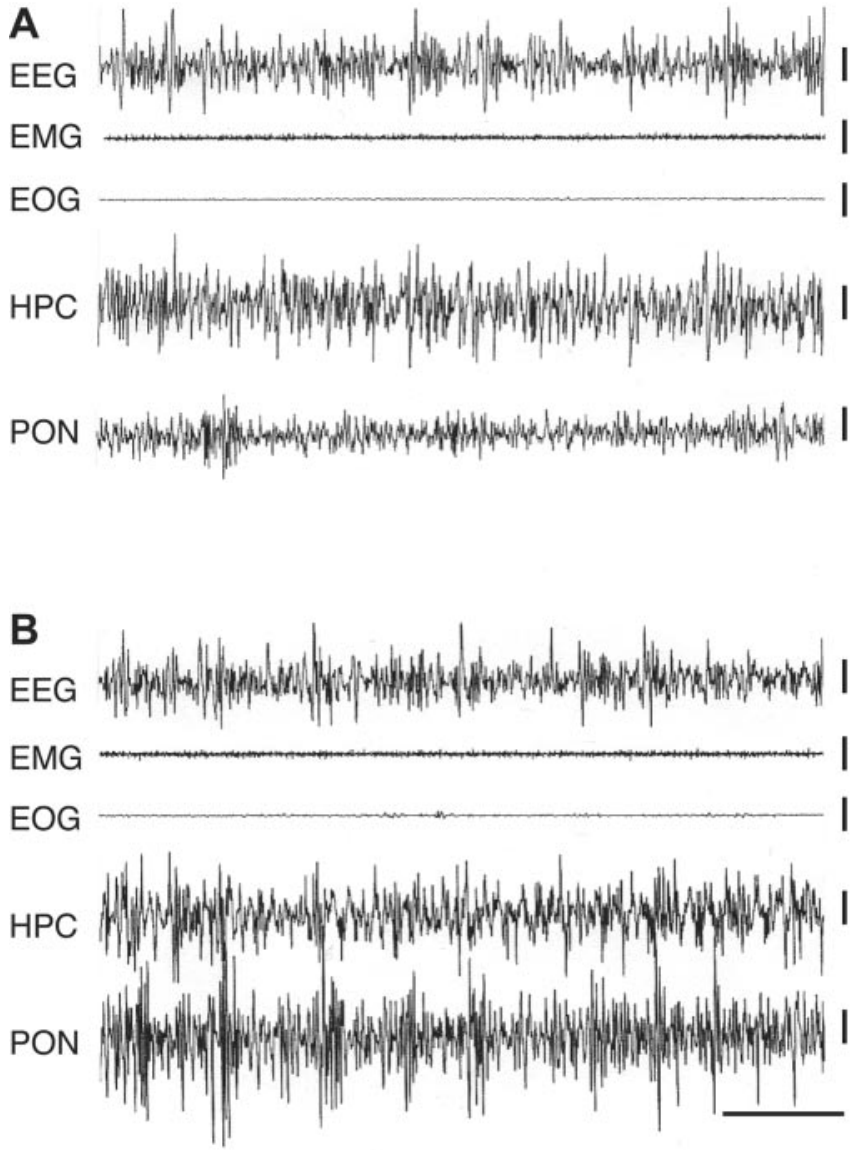

Figure 3. Local application of carbachol into the P-wave generator induced stateindependent $P$-waves during SWS. Sample polygraphic signs of $S W S$ after a session of learning training trials followed by microinjection of control saline $(A)$ or microinjection of carbachol $(B)$ into the P-wave generator. Note the qualitative similarity in both records showing characteristic electroencephalographic signs of SWS: high amplitude, low-frequency waves recorded from the frontal cortex (EEG), reduced muscle tone recorded from the neck (EMG), absence of eye movements (EOG), and non-theta-type EEG recorded from the hippocampus (HPC). Despite qualitative similarity, microinjection of carbachol into the P-wave generator $(B)$ induced P-waves (PON) that are normally absent during SWS without cholinergic activation of the P-wave generator $(A)$.

RSD-PA animals $(7250 \pm 67)$ was also significantly higher (98.5\% higher; $F=39.5$; $p<0.001)$ compared with group NSC animals (3654 \pm 98$)$. These results demonstrate that the application of carbachol into the P-wave generator of group RSD-PA animals increased $\mathrm{P}$-wave density by activating the $\mathrm{P}$-wave generator.

\section{REM sleep deprivation and $\mathrm{P}$-wave generator activation:}

effects on avoidance learning

Learning performance on the shuttle box avoidance task is shown in Figure 4. The data on percentage of avoidance during the training trials session showed no significant variation between the three different groups of rats (two-way ANOVA; group $\times$ block). Because there was no group effect, avoidance data of these three groups during training trials were combined to compare with avoidance data in the test sessions. Combined avoidance data during training sessions was then compared separately with test trial sessions of the three different treatment groups. The twoway ANOVA indicated a significant main effect of session $\left(F_{(3,56)}=62.65 ; p<0.001\right)$ and blocks of trial $\left(F_{(5,56)}=19.12\right.$; 


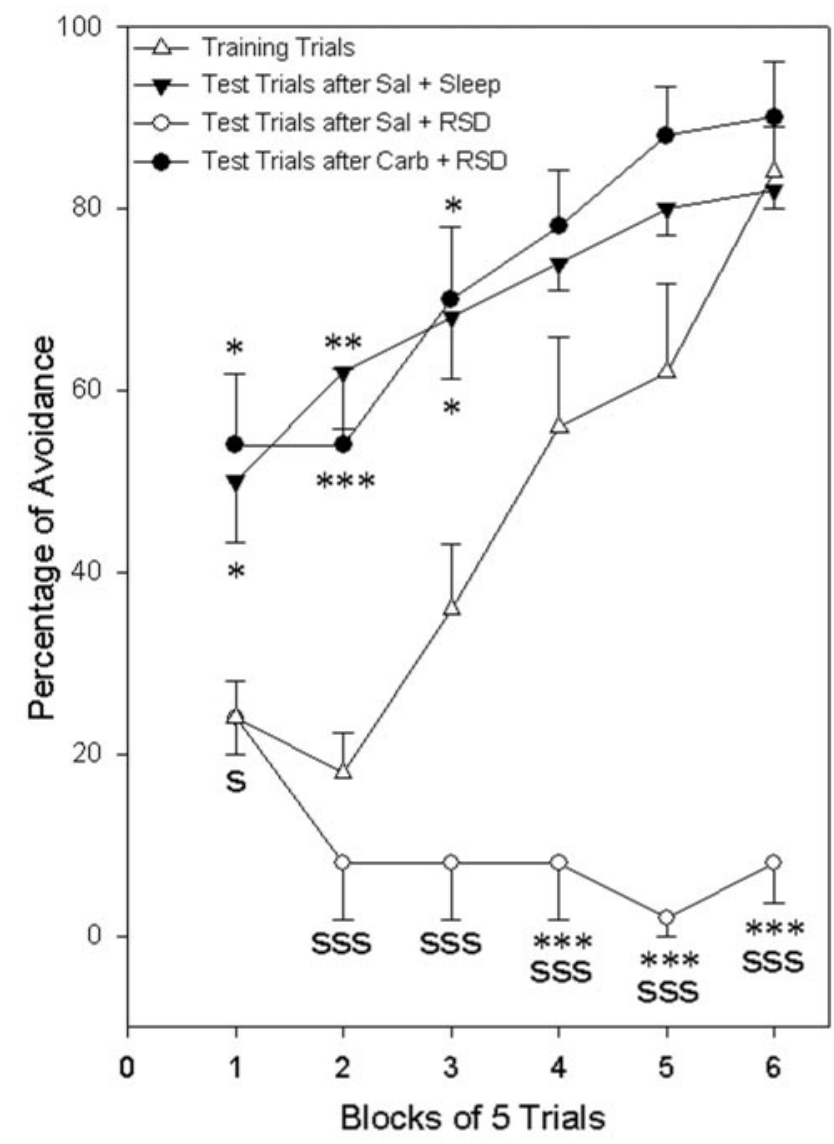

Figure 4. Carbachol microinjection into the P-wave generator prevents post-training REM sleep deprivation-induced learning impairments. The percentage of avoidance learning (mean $\pm \mathrm{SE}$ ) is plotted here in blocks of five trials. Note that in the training trials session $(\triangle$, control group) the rats performed poorly in the first two blocks of trials and started to avoid in the third block. By the sixth block, the animals successfully avoided in $>80 \%$ of the trials. After the training trials, after a control saline injection into the P-wave generator, the animals were allowed $6 \mathrm{hr}$ of undisturbed sleep $(\mathbf{\Delta})$. After sleep, animals were subjected to test trials of avoidance learning. Unlike in the training trials, during the first two blocks of test trials, animals avoided in $>50 \%$ of the trials. These data demonstrate the improvement in the avoidance learning (or retention) between training and test trials. All groups received the same initial training. Note that the group that subsequently received a control saline microinjection and selective REM sleep deprivation did not show any improvement in the test trials $(\bigcirc)$. These data indicate that the selective REM sleep deprivation caused a deficit of retention and improvement in the test trials. This selective REM sleep deprivation also caused a deficit in the acquisition process in the test trials. After training trials, animals microinjected with carbachol into the P-wave generator and deprived of REM sleep did not show any deficit in learning improvement (retention) or acquisition in the test trials $(\mathbf{O})$. This observation indicates that the microinjection of carbachol into the P-wave generator was as effective as post-training undisturbed REM sleep for the retention and acquisition of avoidance learning in the test trials. Post hoc Scheffé $F$ test: asterisk represents the comparison between training and test trials, and " $S$ " represents comparison of test trials between the control group and experimental groups. $S$ or ${ }^{*} p<0.05$; ${ }^{* *} p<0.01 ;$ SSS or ${ }^{* * *} p<0.001$.

$p<0.001)$. Post hoc statistical analysis (Scheffé $F$ test) showed that the percentages of avoidance in the test trial session of group NSC were significantly higher in the first $(108.3 \%$ higher; $F=$ $3.189 ; p<0.05)$, second (244.4\% higher; $F=7.582 ; p<0.001)$, and third $(88.9 \%$ higher; $F=3.421 ; p<0.05)$ blocks of trials compared with the percentages of avoidance in the first, second, and third blocks of the training trials session (Fig. 4). The percentages of avoidance in group NSC were also higher in the fourth (32.1\% higher) and fifth (29.0\% higher) blocks of the test trials session compared with those from the training trials session, but these differences did not reach statistical significance.
These results demonstrate that in the test trials session, after a period of undisturbed sleep-wake activity, the performance of group NSC animals on the avoidance-learning task improved significantly compared with the training session. Similar post hoc analysis revealed that the percentages of avoidance in the test trials session of group RSD were significantly less than the training trials in the second, third, fourth, fifth, and sixth blocks of trials (Fig. 4). In the first two blocks of trials during the test trials session, group RSD animals moved around apparently not attending to the CS-UCS and appeared to be fearless. During the subsequent blocks of trials they exhibited a mixture of freezing and aggressive responses to each CS that outlasted the UCS period. This apparent fearlessness, freezing, and aggressive response to the CS-UCS could help explain the poor avoidance performance in group RSD animals. These results demonstrated that in the test trials session, the performance of group RSD animals not only did not follow the normal course of improvement over the trials, but also actually worsened over time (Fig. 4). These results indicate a deficit in the reacquisition as well as retention processes of avoidance learning after REM sleep deprivation after normal training trials. Post hoc analysis revealed that the percentages of avoidance in the test trials session of group RSD were significantly less compared with group NSC (Fig. 4). These results support other evidence showing that REM sleep deprivation between training trials and test trials prevents improvement of avoidance learning on the test trials. These results also indicate that REM sleep deprivation immediately after test trials disrupts the avoidance-learning acquisition process.

Having documented deficits in the acquisition and retention processes of avoidance learning after REM sleep deprivation, we next quantified the consequences of $\mathrm{P}$-wave generator activation before REM sleep deprivation. In group RSD-PA, as in group NSC, the percentages of avoidance in the test trials session were significantly higher in the first $(125.0 \%$ higher; $F=4.245 ; p<$ 0.05 ), second $(200.0 \%$ higher; $F=5.076 ; p<0.01)$, and third (94.4\% higher; $F=3.862 ; p<0.05)$ blocks of trials compared with the percentages of avoidance in the first, second, and third blocks of the training trials session (Fig. 4). The percentages of avoidance in group RSD-PA, as in group NSC, were also higher in the fourth (39.3\% higher) and fifth (41.9\% higher) blocks of test trials compared with those in the training trials session, but these differences did not reach statistical significance (Fig. 4). These results demonstrate that in the test trials session, the performance of group RSD-PA animals on the avoidance-learning task significantly improved relative to the training session. Statistical comparisons (Scheffé $F$ test) of percentages of avoidance in the test trials between groups RSD and RSD-PA revealed that the percentages of avoidance in group RSD-PA animals were significantly higher than group in RSD animals in all six blocks of trials (Fig. 4). These differences indicate that the rats that received the carbachol microinjection into the P-wave generator before REM sleep deprivation performed better on the avoidance-learning task. Statistical comparison between the test trials sessions of groups NSC and RSD-PA revealed no significant differences in the percentages of avoidance (Fig. 4). These results indicate that despite REM sleep deprivation, the acquisition and retention processes of group RSD-PA animals remained normal. Together, these statistical comparisons (Scheffé $F$ tests) between the different combinations of groups NSC, RSD, and RSD-PA reveal that the microinjection of carbachol into the P-wave generator after training trials can completely prevent REM sleep deprivationinduced deficits in retention from the training trials and facilitate 
acquisition processes in the test trials of two-way active avoidance learning.

In this study, microinjection of carbachol into the $\mathrm{P}$-wave generator rescued REM sleep deprivation-induced deficit in the improvement of learning performance. Is it possible that the microinjection of carbachol into the P-wave generator might have diffused into the neighboring structure, the locus coeruleus? Hypothetically, diffusion of carbachol into the locus coeruleus may increase motor performance by activating noradrenergic cells in the locus coeruleus (Berridge and Foote, 1991, 1996). We believe that carbachol microinjected into the P-wave generator did not diffuse into the locus coeruleus or any other major structures of the brainstem, for the following reasons. First, in our earlier $\mathrm{P}$-wave generator mapping study, we showed that $100 \mathrm{nl}$ of carbachol or BDA microinjection into the $\mathrm{P}$-wave generator diffuses only 0.1-0.15 mm in diameter (Datta et al., 1998, 1999, 2003). Second, previous studies by other investigators have shown that the microinjections of $100 \mathrm{nl}$ volume of drug into the brainstem can effectively diffuse only $0.3-0.5 \mathrm{~mm}$ from the center of an injection site (Myers and Hoch, 1978; Vanni-Mercier et al., 1989; Vertes et al., 1993). Third, carbachol microinjection into the locus coeruleus suppresses slow-wave sleep by increasing wakefulness (Berridge and Foote, 1991, 1996), and in this study carbachol microinjection into the $\mathrm{P}$-wave generator did not change the total amount of slow-wave sleep. Therefore, it is not likely that the microinjection of carbachol into the P-wave generator directly activated the locus coeruleus. Fourth, the activation of neighboring structures like the dorsal raphe and locus coeruleus suppresses P-wave activity, but in this study, carbachol microinjections into the P-wave generator induced $\mathrm{P}$-wave activity. Taken together, this evidence indicates that it is highly unlikely that the carbachol microinjection-induced improvement in learning behavior was caused by the diffusion of carbachol in structures other than the P-wave generator. Finally, in the present study, histological examination confirmed that the $100 \mathrm{nl}$ volume of dye diffused only $0.1 \mathrm{~mm}$ from the center of the microinjection (Fig. 1).

\section{Relationship between P-wave density and improvement in avoidance learning}

Because the REM sleep P-wave density of group NSC increased significantly during the experimental recording session, and because in our earlier study we demonstrated a positive correlation between the post-training REM sleep P-wave density and improvement of learning in the retest session (Datta, 2000), we expected to see a precise relationship between the REM sleep $\mathrm{P}$-wave density change from baseline to experimental recording sessions and the improvement in performance. Indeed, a strong correlation was observed (Pearson correlation coefficient: $r=$ $0.84 ; F=44.59 ; p=0.0002$ ) (Fig. 5 ). These results suggest that the increase in $\mathrm{P}$-wave density during REM sleep after training trials is correlated with effective task performance in the test trials. Next, to determine the correlation between the P-wave generator activation-induced $\mathrm{P}$-wave density change and improvement of performance in RSD-PA group, P-wave density change was calculated by subtracting baseline $\mathrm{P}$-wave density (expressed as waves per minute for the entire $6 \mathrm{hr}$ period) from the $\mathrm{P}$-wave density in the post-training recording session. This carbacholinduced P-wave density change in group RSD-PA showed a statistically significant positive slope with the percentage of improvement in the test trials session $(r=0.93 ; F=116.5 ; p=$ 0.0001). These results demonstrate that the level of $\mathrm{P}$-wave generator activation after training trials is directly correlated with the improvement in the test trials.
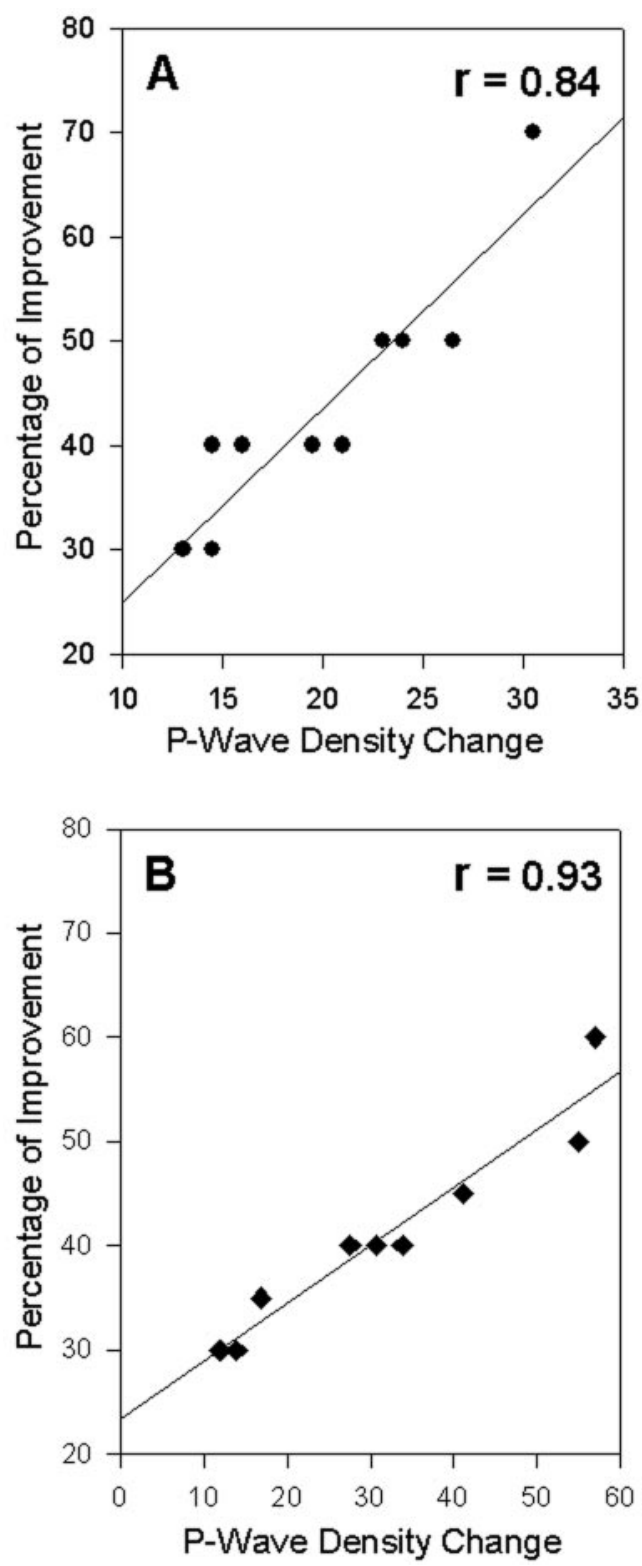

Figure 5. Relationship between the $\mathrm{P}$-wave density change and the improvement in avoidance learning. $A$, The percentage of improvement for each animal $(\mathcal{)})$ is shown as a function of the percentage of REM sleep P-wave density change between the last baseline recording session and the post-training recording session ( $n=10$ rats). The plot of linear regression best-fit (solid line; Pearson product-moment correlation) shows a statistically significant positive slope $(r=0.84 ; p<0.001)$. These data indicate that the level of improvement of learning in the test session depends positively on the percentage of $\mathrm{P}$-wave density increase during post-training REM sleep. $B$, The percentage of improvement for each animal (filled rectangles) is shown as a function of the percentage of $P$-wave density change (for the entire $6 \mathrm{hr}$ period) between the last baseline recording session and post-training P-wave generator carbachol-microinjected recording session ( $n=10$ rats). The plot of linear regression best-fit (solid line; Pearson product-moment correlation) shows a statistically significant positive slope ( $r=0.93 ; p<$ 0.001). These data indicate that the level of improvement of learning in the test session is proportional to the carbachol microinjection-induced state-independent $\mathrm{P}$-wave density.

\section{Discussion}

The principal findings of this study are that (1) a newly designed REM sleep deprivation method selectively eliminated REM sleep without changing SWS, (2) REM sleep deprivation after training trials prevented improvement on test trial performance, (3) microinjection of carbachol into the $\mathrm{P}$-wave generator after training trials prevented REM sleep deprivation-induced deficits in learn- 
ing improvement, and (4) improved learning performance during the test trial session was proportional to the level of P-wave generator activation. These results suggest that the activation of the P-wave generator during REM sleep enhances a physiological process of memory processing that occurs naturally during postlearning REM sleep.

\section{Methodological considerations}

Since the discovery of REM sleep, animal studies of sleep and learning have used various hippocampally and nonhippocampally mediated learning paradigms. In this study, we have used a TWAA-learning task that involves both the hippocampus and the amygdala (Smith and Young, 1980; Ambrosini et al., 1988; Ramirez and Carrer, 1989; Bramham et al., 1994; Mavanji and Datta, 2003). One recent anatomical study provided evidence that $\mathrm{P}$-wave-generating cells project monosynaptically to both hippocampal and non-hippocampal structures involved in learning processes (Datta et al., 1998). Two other studies have shown that the $\mathrm{P}$-wave generator activity in post-training periods is directly related to the TWAA-learning improvement in test trials (Datta, 2000; Mavanji and Datta, 2003). Therefore, the selection of a TWAA-learning task was appropriate for this study.

\section{Effects of avoidance learning on sleep-wake states}

The present study demonstrates that after learning trials, rats spent $27.2 \%$ more time in REM sleep compared with baseline. These results agree with previous animal studies that have shown consistently that both appetitive and aversive training increase REM sleep in the post-training period (Smith and Wong, 1991; Bramham et al., 1994; Giuditta et al., 1995; Smith and Rose, 1997; Datta, 2000; Mavanji and Datta, 2003). Previous studies have demonstrated that control rats subjected to nonlearning, noncontingent TWAA shock trials and rats subjected to passive avoidance-training trials spent significantly less time in REM sleep than they did during baseline recording days (Datta, 2000; Mavanji et al., 2003). Thus, in the present study, this increase in REM sleep after TWAA trials may be logically considered to be attributable to learning rather than to foot shock-induced stress. After avoidance-learning trials, the total percentage of time in tS-R increased as well (Datta, 2000; Mavanji and Datta, 2003). The P-wave is normally expressed during both tS-R and REM sleep (Datta, 1997, 2000). During the post-training period, both tS-R and REM sleep increased, showing a heightened demand for P-wave-related behavioral states. The finding that TWAAlearning trials do not significantly change the total amount of SWS and wakefulness is compatible with previous studies (Smith and Rose, 1997; Datta, 2000; Mavanji and Datta, 2003). After training trials, REM sleep P-wave density was $54 \%$ greater than it was during the baseline recording session. This increased REM sleep P-wave density after training trials is compatible with our previous study (Datta, 2000; Mavanji and Datta, 2003). These earlier studies suggested a role for the $\mathrm{P}$-wave generator in the learning and memory processing, but the current study indicates that role specifically after acquisition. Taken together, these animal studies indicate that after acquisition, increased P-wave generator activity is critical for learning and memory formation. These results provide further evidence that learning and memory processing require a homeostatic demand for activation of the $\mathrm{P}$-wave generator (Datta, 2000).

\section{Effects of REM sleep deprivation on learning performance} Using this new selective REM sleep deprivation method, the present study demonstrates that post-training REM sleep depri- vation totally blocked the expected improvement on task performance on subsequent retesting. These results agree with previous animal studies using various sleep-deprivation protocols and learning test paradigms that have consistently shown that post-training REM sleep deprivation can partially or even totally block improved performance (Fishbein, 1971; Pearlman, 1973; Pearlman and Becker, 1973; Shiromani and Fishbein, 1979; Smith and Butler, 1982; Smith et al., 1998). In addition to mechanical deprivation methods, another study has shown that during the post-training REM sleep window, intraperitoneal injection of the general protein synthesis inhibitor anisomycin and the cholinergic antagonist scopolamine induces marked learningmemory impairment in the rat (Smith et al., 1991). This evidence suggests that post-training REM sleep is critical for the improvement of learning performance. Post-training REM sleepdependent improvement in learning indicates that increased REM sleep after training trials may be involved in some physiological processes that influence the retention of learned behavior. The present study demonstrates that after a $6 \mathrm{hr}$ period of REM sleep deprivation, the expected improvement in acquisition of active avoidance learning is absent. This observation indicates that under normal conditions REM sleep is critical for normal acquisition, a crucial process of learning and memory.

\section{P-wave generator activation: effects on REM sleep deprivation-induced impairment}

During the post-training sleep recording session, $\mathrm{P}$-wave activity increased proportionally to the improved learning performance in the test session. This finding is in agreement with the earlier study that indicated a relationship between post-training REM sleep P-wave activity and improvement of learning performance (Datta, 2000). Another study has shown that after training trials, immediate supplemental activation of the $\mathrm{P}$-wave generator above the normal post-training increase in $\mathrm{P}$-wave activity increases retention of learning in the retest trials (Mavanji and Datta, 2003). Together, these results indicate that the activation of the P-wave generator during REM sleep after training trials may be involved in the improvement of learning performance on test trials. The present study demonstrates, for the first time, that the post-training REM sleep deprivation-induced deficits in the improvement of learning performance and acquisition during test trials can be completely blocked by activating the P-wave generator immediately after training trials and before the beginning of REM sleep deprivation. As in previous studies (Datta et al., 1999, 2003; Mavanji and Datta, 2003), in this study microinjection of carbachol into the P-wave generator did not significantly change motor activities. Thus, this improvement of learning performance after cholinergic activation of the $\mathrm{P}$-wave generator is not likely caused by increased motor activities. In evaluating the outcome of the present study, however, it is important to acknowledge at the outset that, at this time, we have no way of ruling out other unknown nonspecific effects of carbachol that may or may not interfere with the subsequent test session. To rule out the possibility of long-lasting, nonspecific effects of carbachol microinjection, the present results point to the need for future studies to test these carbachol-microinjected rats at much longer intervals than the $6 \mathrm{hr}$.

\section{Sleep-dependent learning and memory processing: possible role of $\mathrm{P}$-wave generator}

On the basis of a number of neurophysiological studies, off-line reactivation of various neuronal structures involved in learning seems to be critical for the consolidation of memories (Pavlides 
and Winson, 1989; Skaggs and McNaughton, 1996; Qin et al., 1997; Kudrimoti et al., 1999; Poe et al., 2000). In these studies, off-line hippocampal reactivations were seen during both nonREM and REM sleep. This reactivation hypothesis of memory consolidation is also supported by a number of electrical stimulation studies (Stein and Chorover, 1968; Erickson and Patel, 1969; Destrade et al., 1973; Landfield et al., 1973; Destrade and Cardo, 1974). These studies reported that mice and rats receiving post-trial hippocampal stimulation showed better retention of learning than control animals. These studies also showed that when the hippocampus was reactivated by electrical stimulation there was no need for sleep for the improvement of learning.

The present study demonstrates that immediately after training trials, the need for REM sleep for the improvement of learning can be substituted by the cholinergic activation of the $\mathrm{P}$-wave generator. This finding extends and gives a specific meaning to those earlier studies that demonstrated that electrical stimulation of the rostral brainstem after training improves performance in the rat (Leconte et al., 1974; DeWeer, 1976; Bloch et al., 1977; Devietti et al., 1977; Sara et al., 1980; Bloch and Laroche, 1981; Hennevin et al., 1989). The improvement in learning performance by post-trial brainstem stimulation was as effective as hippocampal stimulation. Post-trial brainstem stimulation was shown to facilitate a classically conditioned association and also the development of associative changes in neuronal activity in the hippocampus (Bloch and Laroche, 1981, 1984). Moreover, when stimulation was administered after each long-term potentiation (LTP)-inducing stimulus, it enhanced the magnitude of LTP at the synapses of the perforant path on dentate granular cells and prolonged its duration by several days. Brainstem stimulation during the post-acquisition period appeared to substitute the need for REM sleep by decreasing the post-training REM sleep elevation and abolishing most of the learning impairment produced by post-trial REM sleep deprivation (Bloch et al., 1977). Although these brainstem stimulation studies did not definitively localize a specific structure, it is well known that the rostral brainstem is an important part of the reticular formation that contains a number of specific cell groups involved in the generation of different signs of REM sleep (Datta, 1995). During REM sleep, different parts of the brainstem are activated to generate different phasic and tonic signs of REM sleep, including P-waves (Vertes, 1984; Datta, 1995, 1997). The present results demonstrate that post-training activation of the $\mathrm{P}$-wave generator is sufficient to improve learning even when REM sleep is absent, indicating that the post-learning trial-increased homeostatic demand for REM sleep may be caused, specifically, by a heightened demand for $\mathrm{P}$-wave generator activity. These results support the hypothesis that the activation of the $\mathrm{P}$-wave generator is part of the mechanism for REM sleep-dependent memory consolidation.

In conclusion, activation of $\mathrm{P}$-wave-generating cells during REM sleep may reactivate the forebrain and cortical memory processing structures to reprocess recently stored information aiding in the maintenance of memory and facilitating its later expression. The activation of the $\mathrm{P}$-wave generator may have a causal role in sleep-dependent learning and memory processing.

\section{References}

Abel T, Lattal KM (2001) Molecular mechanisms of memory acquisition, consolidation and retrieval. Curr Opin Neurobiol 11:180-187.

Abel T, Nguyen PV, Barad M, Deuel TA, Kandel ER, Bourtchouladze R (1997) Genetic demonstration of a role for PKA in the late phase of LTP and in hippocampus-based long-term memory. Cell 88:615-626.

Ambrosini MV, Sadile AG, Gironi-Carnevale UA, Mattiaccio A, Giuditta A (1988) The sequential hypothesis of sleep function. II. A correlative study between sleep variables and newly synthesized brain DNA. Physiol Behav 43:339-350.

Berridge CW, Foote SL (1991) Effects of locus coeruleus activation of electroencephalographic activity in neocortex and hippocampus. J Neurosci 11:3135-3145.

Berridge CW, Foote SL (1996) Enhancement of behavioral and electroencephalographic indices of waking after stimulation of noradrenergic b-receptors within the medial septal region of the basal forebrain. J Neurosci 16:6999-7009.

Bhanot JL, Chinna GS, Singh B, Sachdeva U, Kumar VM (1989) REM sleep deprivation and food intake. Ind J Physiol Pharmacol 33:139-145.

Bloch V, Laroche S (1981) Conditioning of hippocampal cells: its acceleration and long-term facilitation by post-trial reticular stimulation. Behav Brain Res 3:23-42.

Bloch V, Laroche S (1984) Facts and hypotheses related to the search for the engram. In: Neurobiology of learning and memory (Lynch G, McGaugh JL, Weinberger NM, eds), pp 249-260. New York: Guilford.

Bloch V, Hennevin E, Leconte P (1977) Interaction between post-trial reticular stimulation and subsequent paradoxical sleep in memory consolidation processes. In: Neurobiology of sleep and memory (Drucker-Colin RR, McGaugh JL, eds), pp 255-272, New York: Academic.

Bramham CR, Srebro B (1989) Synaptic plasticity in the hippocampus is modulated by behavioral state. Brain Res 493:74-86.

Bramham CR, Maho C, Laroche S (1994) Suppression of long-term potentiation induction during alert wakefulness but not during "enhanced" REM sleep after avoidance learning. Neuroscience 59:501-509.

Brooks DC, Bizzi E (1963) Brain stem electrical activity during deep sleep. Arch Ital Biol 101:648-665.

Campbell IG, Guinan ML, Horowitz JM (2002) Sleep deprivation impairs long-term potentiation in rat hippocampal slices. J Neurophysiol 88:1073-1076.

Cohen NJ, Squire LR (1980) Preserved learning and retention of patternanalyzing skill in amnesia: dissociation of knowing how and knowing that. Science 210:207-210.

Datta S (1995) Neuronal activity in the peribrachial area: relationship to behavioral state control. Neurosci Biobehav Rev 19:67-84.

Datta S (1997) Cellular basis of pontine ponto-geniculo-occipital wave generation and modulation. Cell Mol Neurobiol 17:341-365.

Datta S (2000) Avoidance task training potentiates phasic pontine-wave density in the rat: a mechanism for sleep-dependent plasticity. J Neurosci 20:8607-8613.

Datta S (2002) Evidence that REM sleep is controlled by the activation of brain stem pedunculopontine tegmental kainate receptor. J Neurophysiol 87:1790-1798.

Datta S, Hobson AJ (1994) Neuronal activity in the caudolateral peribrachial pons: relationship to PGO waves and rapid eye movements. J Neurophysiol 71:95-109.

Datta S, Hobson AJ (1995) Suppression of ponto-geniculo-occipital waves by neurotoxic lesions of pontine caudo-lateral peribrachial cells. Neuroscience 67:703-712.

Datta S, Calvo JM, Quatrochi JJ, Hobson JA (1992) Cholinergic microstimulation of the peribrachial nucleus in the cat. I. Immediate and prolonged increases in ponto-geniculo-occipital waves. Arch Ital Biol 130:263-284.

Datta S, Siwek DF, Patterson EH, Cipolloni PB (1998) Localization of pontine PGO wave generation sites and their anatomical projections in the rat. Synapse 30:409-423.

Datta S, Patterson EH, Siwek DF (1999) Brainstem afferents of the cholinoceptive pontine wave generation sites in the rat. Sleep Res Online 2:79-82.

Datta S, Spoley EE, Patterson EH (2001) Microinjection of glutamate into the pedunculo pontine tegmentum induces REM sleep and wakefulness in the rat. Am J Physiol 280:R752-R759.

Datta S, Spoley EE, Mavanji VK, Patterson EH (2002) A novel action of pedunculopontine tegmental kainate receptors: a mechanism of REM sleep generation in the rat. Neuroscience 114:157-164.

Datta S, Mavanji VK, Patterson EH, Ulloor J (2003) Regulation of rapid eye movement sleep in the freely moving rat: local microinjection of serotonin, norepinephrine, and adenosine into the brainstem. Sleep 26:513-520.

Destrade C, Cardo B (1974) Effects of post-trial hippocampal stimulation on time-dependent improvement of performance in mice. Brain Res 78:447-454. 
Destrade C, Soumireu-Mourat B, Cardo B (1973) Effects of posttrial hippocampal stimulation on acquisition of operant behavior in the mouse. Behav Biol 8:713-724.

Devietti TL, Conger GL, Kirkpatrick BR (1977) Comparison of the enhancement gradients of retention obtained with stimulation of the mesencephalic reticular formation after training or memory reactivation. Physiol Behav 19:549-554.

DeWeer B (1976) Selective facilitative effect of post-trial reticular stimulation in discriminative learning in the rat. Behav Proc 1:243-257.

Dujardin K, Guerrien A, Leconte P (1990) Sleep, brain activation and cognition. Physiol Behav 47:1271-1278.

Erickson CK, Patel JB (1969) Facilitation of avoidance learning by posttrial hippocampal electrical stimulation. J Comp Physiol Psychol 68:400-406.

Feng P, Vogel GW, Obermeyer W, Kinney GG (2000) An instrumental method for long-term continuous REM sleep deprivation of neonatal rats. Sleep 23:175-183.

Fishbein W (1971) Disruptive effects of rapid eye movement sleep deprivation on long term-memory. Physiol Behav 6:279-282.

Fishbein W, Gutwien BM (1977) Paradoxical sleep and memory storage processes. Behav Biol 19:425-464.

Frank MG, Issa NP, Stryker MP (2001) Sleep enhances plasticity in the developing visual cortex. Neuron 30:275-287.

Gabrieli JDE (1998) Cognitive neuroscience of human memory. Annu Rev Psychol 49:87-115.

Gallagher M, McMahan RW, Schoenbaum G (1999) Orbitofrontal cortex and representation of incentive value in associative learning. J Neurosci 19:6610-6614.

Giuditta A, Ambrosini MV, Montagnese P, Mandile P, Cotugno M, Grassi Zucconi G, Vescia S (1995) The sequential hypothesis of the function of sleep. Behav Brain Res 69:157-166.

Graves L, Pack A, Abel T (2001) Sleep and memory: a molecular perspective. Trends Neurosci 24:237-243.

Guzman-Marin R, Suntsova N, Stewart DR, Gong H, Szymusiak R, McGinty D (2003) Sleep deprivation reduces proliferation of cells in the dentate gyrus of the hippocampus in rats. J Physiol (Lond) 549:563-571.

Hamdi A (2000) Regulation of cardiac and renal peripheral benzodiazepine receptor binding in rapid eye movement sleep-deprived rats. Life Sci 67:3015-3022.

Hatfield T, Han J-S, Conley M, Gallagher M, Holland P (1996) Neurotoxic lesions of basolateral, but not central, amygdala interfere with Pavlovian second-order conditioning and reinforcer devaluation effects. J Neurosci 16:5256-5265.

Hennevin E, Hars B, Bloch V (1989) Improvement of learning by mesencephalic reticular stimulation during postlearning paradoxical sleep. Behav Neural Biol 51:291-306.

Hicks RA, Okuda A, Thomsen D (1997) Depriving rats of REM sleep: the identification of a methodological problem. Am J Psychol 90:95-102.

Izquierdo I, Fin C, Schmitz PK, DaSilva RC, Jerusalinsky D, Quillfeldt JA, Ferreira MBG, Medina JH, Bazan NG (1995) Memory enhancement by intrahippocampal, intraamygdala, or intraentorhinal infusion of plateletactivating factor measured in an inhibitory avoidance task. Proc Natl Acad Sci USA 92:5047-5051.

Karni A, Tanne D, Rubenstein BS, Askenasy JJ, Sagi D (1994) Dependence on REM sleep of overnight improvement of a perceptual task. Science 265:679-682.

Kesner RP (1998) Neurobiological views of memory. In: Neurobiology of learning and memory (Martinez Jr JL, Kesner RP, eds), pp 361-416. San Diego: Academic.

Kim JJ, Baxter MG (2001) Multiple brain-memory systems: the whole does not equal the sum of its parts. Trends Neurosci 24:324-330.

Kudrimoti HS, Barnes CA, McNaughton BL (1999) Reactivation of hippocampal cell assemblies: effects of behavioral state, experience, and EEG dynamics. J Neurosci 19:4090-4101.

Landfield PW, Tusa RJ, McGaugh JL (1973) Effects of posttrial hippocampal stimulation memory storage and EEG activity. Behav Biol 8:485-505.

Laurent JP, Ayalaguerrero F (1975) Reversible suppression of pontogeniculo-occipital waves by localized cooling during paradoxical sleep in cats. Exp Neurol 49:356-369.

Leconte P, Hennevin E, Bloch V (1974) Duration of paradoxical sleep necessary for the acquisition of conditioned avoidance in the rat. Physiol Behav 13:675-681.
LeDoux JE (1992) Emotion and the amygdala. In: The amygdala: neurobiological aspects of emotion, memory, and mental dysfunction (Aggleton J, ed), pp 339-351. New York: Wiley.

Louie K, Wilson MA (2001) Temporally structured replay of awake hippocampal ensemble activity during rapid eye movement sleep. Neuron 29:145-156.

Maquet P, Smith C, Stickgold R (2003) Sleep and brain plasticity. Oxford: Oxford UP.

Mavanji V, Datta S (2003) Activation of the phasic pontine-wave generator enhances improvement of learning performance: a mechanism for sleepdependent plasticity. Eur J Neurosci 17:359-370.

Mavanji VK, Siwek DF, Patterson EH, Spoley EE, Datta S (2003) Effects of passive-avoidance training on sleep-wake state-specific activity in the basolateral and central nuclei of the amygdala. Behav Neurosci 117:751-759.

McGrath MJ, Cohen DB (1978) REM sleep facilitation of adaptive waking behavior: a review of the literature. Psychol Bull 85:24-57.

Myers RD, Hoch B (1978) 14-C dopamine microinjected into the brainstem of rat: dispersion kinetics, site content and functional dose. Brain Res Bull 3:601-609.

Ocampo-Garces A, Molina E, Rodriguez A, Vivaldi EA (2000) Homeostasis of REM sleep after total and selective sleep deprivation in the rat. J Neurophysiol 84:2699-2702.

Pavlides C, Winson J (1989) Influences of hippocampal place cell firing in the awake state on the activity of these cells during subsequent sleep episodes. J Neurosci 9:2907-2918.

Paxinos G, Watson C (1997) The rat brain in stereotaxic coordinates. San Diego: Academic.

Pearlman C (1973) REM sleep deprivation impairs latent extinction in rats. Physiol Behav 11:233-237.

Pearlman C (1979) REM sleep and information processing: evidence from animal studies. Neurosci Biobehav Rev 3:57-68.

Pearlman C, Becker M (1973) Brief posttrial REM sleep deprivation impairs discrimination learning in rats. Physiol Psychol 1:373-376.

Poe GR, Nitz DA, McNaughton BL, Barnes CA (2000) Experiencedependent phase-reversal of hippocampal neuron firing during REM sleep. Brain Res 855:176-180.

Poremba A, Gabriel M (1997) Amygdalar lesions block discriminative avoidance learning and cingulothalamic training-induced neuronal plasticity in rabbits. J Neurosci 17:5237-5244.

Qin Y, McNaughton BL, Skaggs WE, Barnes CA (1997) Memory reprocessing in cortico-cortical and hippocampo-cortical neuronal ensembles. Philos Trans R Soc Lond B Biol Sci 352:1525-1533.

Ramirez OA, Carrer HF (1989) Correlation between threshold to induce long-term potentiation in the hippocampus and performance in a shuttle box avoidance response in rats. Neurosci Lett 104:152-156.

Rechtschaffen A, Bergmann BM (1995) Sleep deprivation in the rat by the disk-over-water method. Behav Brain Res 69:55-63.

Rechtschaffen A, Bergmann BM, Everson CA, Kushida CA, Gilliland MA (1989) Sleep deprivation in the rat: X. Integration and discussion of the findings. Sleep 12:68-87.

Rechtschaffen A, Bergmann BM, Gilliland MA, Bauer K (1999) Effects of method, duration, and sleep stage on rebounds from sleep deprivation in the rat. Sleep 22:11-31.

Rempel-Clower NL, Zola SM, Squire LR, Amaral DG (1996) Three cases of enduring memory impairment after bilateral damage limited to the hippocampal formation. J Neurosci 16:5233-5255.

Ribeiro S, Goyal V, Mello CV, Pavlides C (1999) Brain gene expression during REM sleep depends on prior waking experience. Learn Mem 6:500-508.

Ribeiro S, Mello CV, Velho T, Gardner TJ, Jarvis ED, Pavlides C (2002) Induction of hippocampal long-term potentiation during waking leads to increased extrahippocampal zif-268 expression during ensuing rapid-eye-movement sleep. J Neurosci 22:10914-10923.

Sakai K, Jouvet M (1980) Brainstem PGO-on cells projecting directly to the cat dorsal lateral geniculate nucleus. Brain Res 194:500-505.

Sakai K, Petitjean F, Jouvet M (1976) Effects of pontomesencephalic lesions and electrical stimulation upon PGO waves and EMPs in unanesthetized cats. Electroencephalogr Clin Neurophysiol 41:49-63.

Sara SJ, Deweer B, Hars B (1980) Reticular stimulation facilitates retrieval of a "forgotten" maze habit. Neurosci Lett 18:211-217. 
Sei H, Saitoh D, Yamamoto K, Morita K, Morita Y (2000) Differential effect of short-term REM sleep deprivation on NGF and BDNF protein levels in the rat brain. Brain Res 877:387-390.

Shiromani P, Fishbein W (1979) Development of learning and memory in mice after brief paradoxical sleep deprivation. Physiol Behav 22:971-978.

Silva AJ, Stevens CF, Tonegawa S, Wang Y (1992) Deficient hippocampal long-term potentiation in alpha-calcium-calmodulin kinase II mutant mice. Science 257:201-206.

Skaggs WE, McNaughton BL (1996) Replay of neuronal firing sequences in rat hippocampus during sleep following spatial experience. Science 271:1870-1873.

Smith C (1985) Sleep states and learning: a review of the animal literature. Neurosci Biobehav Rev 9:157-168.

Smith C (1995) Sleep states and memory processes. Behav Brain Res 69:137-145

Smith C, Butler S (1982) Paradoxical sleep at selective times following training is necessary for learning. Physiol Behav 29:469-473.

Smith C, Rose GM (1997) Posttraining paradoxical sleep in rats is increased after spatial learning in the Morris water maze. Behav Neurosci 111:1197-1204.

Smith C, Wong PTP (1991) Paradoxical sleep increases predict successful learning in a complex operant task. Behav Neurosci 105:282-288.

Smith C, Young J (1980) Reversal of paradoxical sleep deprivation by amygdaloid stimulation during learning. Physiol Behav 24:1035-1039.

Smith C, Tenn C, Annett R (1991) Some biochemical and behavioral aspects of the paradoxical sleep window. Can J Psychol 45:115-125.

Smith C, Conway JM, Rose GM (1998) Brief paradoxical sleep deprivation impairs reference, but not working, memory in the radial arm maze task. Neurobiol Learn Mem 69:211-217.

Squire LR, Amaral DG, Press GA (1990) Magnetic resonance imaging of the hippocampal formation and mammillary nuclei distinguish medial temporal lobe diencephalic amnesia. J Neurosci 10:3106-3117.
Stefurak SJ, Stefurak ML, Mendelson WB, Gillin JC, Wyatt RJ (1977) A method for sleep depriving rats. Pharmacol Biochem Behav 1:137-139.

Stein DG, Chorover S (1968) Effects of post-trial electrical stimulation of hippocampus and caudate nucleus on maze learning in the rat. Physiol Behav 3:787-791.

Stickgold R (1998) Sleep: off-line memory reprocessing. Trends Cogn Sci 2:484-492.

Thakkar M, Mallick BN (1993) Rapid eye movement sleep-deprivationinduced changes in glucose metabolic enzymes in rat brain. Sleep 16:691-694.

Vanni-Mercier G, Sakai K, Lin JS, Jouvet M (1989) Mapping of cholinoceptive brainstem structures responsible for the generation of paradoxical sleep in the cat. Arch Ital Biol 127:133-164.

Vazdarjanova A, McGaugh JL (1999) Basolateral amygdala is involved in modulating consolidation of memory for classical fear conditioning. J Neurosci 19:6615-6622.

Vertes RP (1984) Brainstem control of the events of REM sleep. Prog Neurobiol 22:241-288

Vertes RP, Colom LV, Fortin WJ, Bland BH (1993) Brainstem sites for the carbachol elicitation of the hippocampal theta rhythm in the rat. Exp Brain Res 96:419-429.

Vogel GW (1975) A review of REM sleep deprivation. Arch Gen Psychiatry 32:749-761.

Vyazovskiy VV, Deboer T, Rudy B, Lau D, Borbely AA, Tobler I (2002) Sleep EEG in mice that are deficient in the potassium channel subunit K.v.3.2. Brain Res 947:204-211.

White NM, McDonald RJ (2002) Multiple parallel memory systems in the brain of the rat. Neurobiol Learn Mem 77:125-184.

Young B, Otto T, Fox GD, Eichenbaum H (1997) Memory representation within the parahippocampal region. J Neurosci 17:5183-5195. 